\title{
Psychiatric Morbidity among a Sample of Orphanage Children in Cairo
}

\author{
Mohamed A. EL Koumi, ${ }^{1}$ Yasser F. Ali, ${ }^{1}$ Ehab A. El Banna, ${ }^{1}$ Usama M. Youssef, ${ }^{2}$ \\ Yasser M. Raya, ${ }^{2}$ and Aly A. Ismail ${ }^{3}$ \\ ${ }^{1}$ Departments of Pediatrics, Faculty of Medicine, Zagazig University, Egypt \\ ${ }^{2}$ Department of Psychiatry, Faculty of Medicine, Zagazig University, Egypt \\ ${ }^{3}$ Department of Psychiatry, Faculty of Medicine, Al Azhar University, Egypt
}

Correspondence should be addressed to Mohamed A. EL Koumi, mohamed_197228@hotmail.com

Received 25 September 2012; Accepted 20 November 2012

Academic Editor: Namik Yaşar Özbek

Copyright (C) 2012 Mohamed A. EL Koumi et al. This is an open access article distributed under the Creative Commons Attribution License, which permits unrestricted use, distribution, and reproduction in any medium, provided the original work is properly cited.

\begin{abstract}
Objective. This study identifies the prevalence of emotional and behavioral problems and the associated factors in orphanage children. Methods. This cross-sectional study was conducted in three private orphanages in Cairo. Two hundred sixty-five children of ages ranging from 6 to 12 years living in three different orphanages care systems were included in the study. A sociodemographic information form and the Child Behavior Checklist (CBCL) were used. Children were clinically interviewed and psychiatric disorders were identified. Diagnoses were done according to the manual for diagnosis and statistics of mental disorder fourth version (DSMIV). A written formal consent from the director of social solidarity was obtained before inclusion in the study. Results. The prevalence of behavioral disturbances was $64.53 \%$ among those in institutional care and the most prominent psychiatric disorders were nocturnal enuresis (23.3\%), attention deficit hyperkinetic disorder (ADHD) (19.62\%), oppositional defiant disorder (17.36\%). Age at first admission, causes of receiving institutional care, and moves 2 or more times between institutions were significantly associated with an increased risk of behavioral and emotional problems. Conclusion. Our study showed that children living in institutions are prone to suffer from psychiatric disorders. Stability of the caregiver acts as a protective variable.
\end{abstract}

\section{Introduction}

Childhood is a developmental stage in which the importance of reciprocal emotional bonding between a child and his/her caregivers, for healthy physical, psychological, and social development has been known for centuries [1]. Orphans in group homes or institutions take more risks, have more threats to achievement, and have poorer peer influences [2]. Almost no systematic studies have been carried out during the past five decades about orphanages largely because nearly all orphanages in industrial nations have been replaced by adoption and foster care [3]. This solution, in Third World Countries, is unacceptable either religiously in some countries as Egypt, or has been considered an unrealistic solution in other countries as in Africa [3]. Although orphanages can provide a secure and positive alternative to abusive and unsafe family or community environments, they cannot provide individualized and family nurturing [4]. Research findings indicate that children in institutional care have more behavioral problems, such as aggressive behavior and have higher levels of depression and anxiety, compared to children that are reared in a family environment [5-7]. Several studies have shown that institutional care has negative effects, especially on young children; however, only a few studies have investigated the prevalence rate of problems among these children, the extent of care service needs, and risk and protective factors by collecting data from multiple informants. Early intervention immediately following institutional care placement is recommended [8-12].

\section{Methods}

This cross-sectional epidemiological study recruited 265 children (190 males and 75 females) of ages ranging from 
6 to 12 years $(\mathrm{X} \pm \mathrm{SD}: 3.35 \pm 0.9$ years $)$ residing in three orphanages in Cairo and who had lived with their caregivers for at least a month during the year 2011 through 2012 . Psychiatric analysis was performed by 3 experienced psychiatrists. Excluded from the survey; children with visual and/or auditory deficits, children younger than 6 years, and those with chronic medical illnesses. Children from orphanage I were 81 , orphanage II were 147, and orphanage III were 37. Children were divided into three groups according to age.

Group 1: included 108 children of ages ranging from 6 to 8 years. Group 2: included 70 children of ages ranging from 8 to 10 years. Group 3: included 87 children of ages ranging from 10 to 12 years. All children were subjected to the following.

(1) Sociodemographic Information Form: this form collected data about risk and protective factors regarding children and their families. Based on the information in each child's file, a social service specialist or a psychologist completed the form. Predictive factors, such as current age, age at first admission, history for admission, gender, place of residence prior to institutional care, the frequency of moving from one institution to another and death of mother/father were recorded.

(2) Child Behavior Checklist (CBCL/6-18): the CBCL is designed to obtain parents'/caregivers' reports of their children's problems. The CBCL was translated to Arabic and its reliability and validity has been established The test retest reliability was 0.84 for total problems and 0.88 for internal consistency. In the validity study, confirmatory factor analysis was conducted and $99 \%$ of the items were found to be significantly, positive, and sufficiently measure what they were designed to measure $(P<0.01)[13]$. The CBCL includes items for rating competencies and 113 items for behavioral and emotional problems. Items are rated on a 3 -pointscale as $0=$ not true, $1=$ sometimes true, and $2=$ often true, based on the preceding 6 months. The following syndromes are scored from the CBCL: Internalizing group (anxious/depressed, withdrawn/depressed, or somatic complaints), externalizing group (rule breaking behavior, or aggressive behavior), social problems, thought problems, and attention problems. [14-16].

(3) Semistructured Psychiatric Interview according to DSM $I V$. To detect presence of psychiatric disorders by a qualified psychiatrist.

\section{Statistical Analysis}

Data were presented as mean \pm standard deviation $(\mathrm{X} \pm$ $\mathrm{SD})$ or percentage (\%). The means of two groups were compared using student's $t$ test. Data were tabulated and statistically analyzed with the statistical package for social sciences (SPPS) version 14 software. $P$ values less than 0.05 were considered significant.
TABLE 1: Sociodemographic characteristics of the studied children.

\begin{tabular}{lcc}
\hline & Number $(n)$ & Percent $(\%)$ \\
\hline Orphanage & & \\
I & 81 & 30.56 \\
II & 147 & 59.47 \\
III & 37 & 13.96 \\
Gender & & \\
$\quad$ Male & 190 & 71.7 \\
Female & 75 & 28.3 \\
Age (years) & & \\
6-7 & 108 & 40.75 \\
8-9 & 70 & 26.41 \\
10-12 & 87 & 32.82 \\
Reasons for institutionalization & & \\
Abandonment & 146 & 55.09 \\
Orphanage & 64 & 24.15 \\
Disturbed family & 55 & 20.75 \\
Moves between institution & & \\
1 & 150 & 56.6 \\
2 & 97 & 36.6 \\
3 & 18 & 6.8 \\
Gender of caregivers & & \\
Male & & \\
Female & & \\
Stability of caregivers & & \\
Unstable & & \\
Less than or equal to 2 years & & \\
More than 2 years & & \\
\hline
\end{tabular}

\section{Results}

Two hundred and seventy five children were identified as being eligible to participate in the study. Of these, caregivers of 10 children declined to participate. This left 265 participating children who were residing with 81 caregivers. More than half the children $71.7 \%$ had been in their current placement for less than 2 years; $74.71 \%$ of children had a female caregiver $64.52 \%$ had a stable caregiver for more than 6 months (Table 1 ).

The range of total score was 31-69 (mean $=43.78$ ); the highest scores were on externalizing, internalizing, and aggressive score and the least was somatic score (Table 2).

The completed Child Behavior Checklist (CBCL) showed 11 Ratings on the questionnaire summarized as a total behavior problems score comprising all items on the checklist. Children had total behavior problems represent $61,13 \%$ of the studied group. The externalizing factors were higher than the internalizing ones ( $60 \%$ versus $58.86 \%$ ); the most predominant problem was attention $(43,77 \%)$ whereas somatic problem was the least (18.11\%) (Table 3).

The psychiatric diagnosis of the whole sample (No. 265) as shown in (Table 4); enuresis (23.03\%) was the commonest diagnosis on axis I and mental retardation $(6 \%)$ on axis II. 
TABle 2: Descriptive statistics for the child behavioral checklist.

\begin{tabular}{|c|c|c|c|c|}
\hline & Minimum & Maximum & Mean & Std. deviation \\
\hline Anxiety subscale & 35 & 60 & 45.31 & 6.52 \\
\hline Withdrawal subscale & 34 & 55 & 45.789 & 7.778 \\
\hline Thought problem & 30 & 35 & 30.99 & 5.50 \\
\hline Somatic complains & 30 & 33 & 31.15 & 6.60 \\
\hline Social problems & 30 & 35 & 32.07 & 6.57 \\
\hline Attention & 30 & 36 & 31.04 & 11.9 \\
\hline Aggression & 31 & 69 & 48.98 & 9.87 \\
\hline Delinquent & 30 & 61 & 40.18 & 7.41 \\
\hline Internalizing subscale & 43 & 69 & 56.47 & 7.77 \\
\hline Externalizing subscale & 31 & 69 & 49.356 & 8.60 \\
\hline
\end{tabular}

TABLE 3: Children identified by the caregivers using CBCL to have behavioral problems.

\begin{tabular}{lcc}
\hline Problem & Number $(n)$ & Percent $(\%)$ \\
\hline Total behavior problems & 162 & 61.13 \\
Externalizing problems & 159 & 60 \\
Internalizing problems & 156 & 58.86 \\
Attention problems & 116 & 43.77 \\
Social problems & 110 & 41.5 \\
Delinquent behavior & 108 & 40.75 \\
Aggressive behavior & 101 & 38.11 \\
Thought problems & 96 & 36.3 \\
Withdrawn & 61 & 23 \\
Anxious/depressed & 53 & 20 \\
Somatic complaints & 48 & 18.11 \\
\hline
\end{tabular}

While on axis I attention deficit hyperactivity disorder (19.62\%), oppositional defiant disorder (17.36\%), sleep disorders (10.75\%) followed by conduct disorder (9.81\%) depression disorder $(7.17 \%)$, separation anxiety disorder (7.17\%), lastly no diagnosis on Axis I (35.47\%), less than (1\%) tics, dysthymia, and schizophrenia.

Statistical correlation is shown between different psychiatric morbidity diagnoses and other variables including age differences, sex of caregiver, stability of caregiver reason for institutionalization, moves between institutions, and length of institutionalization (Tables 5(a) and 5(b)).

\section{Discussion}

Lately, an increase in the number of orphanages in many of the Egyptian governorates was noticed as a response of the orientation that encourages the care for the orphans. Many child care professionals are still believing that orphanages are bad for children and they will fail to have a normal development both socially and psychologically [17]. Orphanage children are uniquely vulnerable to many psychosocial hazards of institutional care [18]. Fisher et al. [12], Vorriat et al. [19], Roy et al. [20], and MacLean [21], compared children in institutional care and children living with their families andere found that institutional care had negative effect on the emotional and behavioral development of children
TABLE 4: Psychiatric diagnoses of the orphans according to DSM IV.

\begin{tabular}{lcc}
\hline Diagnoses & Number $(n)$ & Percent $(\%)$ \\
\hline At least one diagnosis & 171 & 64.53 \\
More than one diagnosis & 95 & 35.85 \\
Enuresis & 61 & 23.03 \\
$\quad$ Nocturnal & 52 & 19.62 \\
$\quad$ Diurnal & 2 & 0.75 \\
$\quad$ Both & 7 & 2.64 \\
ADHD & 52 & 19.62 \\
$\quad$ Hyperactivity & 36 & 13.58 \\
$\quad$ Attention deficit & 10 & 3.77 \\
$\quad$ Both & 6 & 2.26 \\
Separation anxiety disorder & 19 & 7.17 \\
Oppositional defiant disorder & 46 & 17.36 \\
Speech disorders & 4 & 1.51 \\
Sleep disorders & 28 & 10.57 \\
Conduct disorder & 26 & 9.81 \\
Depression & 19 & 7.17 \\
Tics & 2 & 0.78 \\
Learning disorders & 6 & 2.26 \\
Dysthymia & 2 & 0.78 \\
Schizophrenia & 1 & 0.38 \\
Mental retardation & 16 & 6 \\
\hline
\end{tabular}

aged 6-12 years. This study of psychiatric and behavioral problems in orphans has revealed that the prevalence rate of total behavior problems was $(61 \%)$, compared to other studies that used CBCL which detected the prevalence rate of behavior problems was nearly $20 \%-78 \%$ [22], and $33 \%$ [17]. In our study the main increase in score of CBCL was in the externalizing factors (hyperactive, aggressive, and delinquent) $60.1 \%$. This denotes the overt aggressive and rebellious attitude of these orphans towards society as they grow up and become more aware of their real condition in the society. They live in conflict that they resolve by indulging in violence. Another cause of this was suggested to be the separation of a child from his/her parents at early ages and the related attachment problems that lead to externalization problems [23]. Cantone et a1. [24]. stated that the internalizing and externalizing factors represent a distinction between fearful inhibited over controlled behavior (internalizing) and aggressive antisocial uncontrolled behavior (externalizing). Other internalizing factors as depressed factor has shown a highly significant increase explained by being deprived of families and lacking the essential psychological support at this early stage of life. The change in total scores of CBCL in the followup was of no statistical significance. In our study, there was statistically significant increase in separation anxiety disorder in children with the lowest age. Offord et al. [25] and Miller et al. [26] had found that frequency and severity of antisocial behavior varied directly with age of adoption. According to the reports of multiple informants, institutionalization at younger ages, the conditions of previous living in another institutions, two or more moves between institutions, and 
TABle 5: (a) Psychiatric diagnoses of the orphans in relation to variables. (b) Psychiatric diagnoses of the orphans in relation to variables.

(a)

\begin{tabular}{|c|c|c|c|c|c|c|c|c|c|c|c|c|}
\hline \multirow[t]{2}{*}{ Variables } & \multicolumn{2}{|c|}{ Enuresis } & \multicolumn{2}{|c|}{ ADHD } & \multicolumn{2}{|c|}{$\begin{array}{l}\text { Separation } \\
\text { anxiety disorder }\end{array}$} & \multicolumn{2}{|c|}{$\begin{array}{l}\text { Oppositional } \\
\text { defiant disorder }\end{array}$} & \multicolumn{2}{|c|}{ Speech disorders } & \multicolumn{2}{|c|}{ Sleep disorders } \\
\hline & $n$ & $P$ & $n$ & $P$ & $n$ & $P$ & $n$ & $P$ & $n$ & $P$ & $n$ & $P$ \\
\hline \multicolumn{13}{|l|}{ Gender } \\
\hline Male & 45 & \multirow[t]{2}{*}{0.108} & 37 & \multirow[t]{2}{*}{0.732} & 13 & \multirow{2}{*}{0.388} & 32 & \multirow{2}{*}{0.786} & 4 & \multirow{2}{*}{0.286} & 22 & \multirow{2}{*}{0.623} \\
\hline Female & 16 & & 15 & & 6 & & 14 & & 0 & & 6 & \\
\hline \multicolumn{13}{|l|}{ Age (years) } \\
\hline $6-8$ & 33 & \multirow{3}{*}{0.0368} & 18 & \multirow{3}{*}{0.055} & 12 & \multirow{3}{*}{$0.0001^{*}$} & 18 & \multirow{3}{*}{0.641} & 2 & \multirow{3}{*}{0.844} & 14 & \multirow{3}{*}{0.399} \\
\hline $8-10$ & 12 & & 19 & & 1 & & 21 & & 1 & & 6 & \\
\hline $10-12$ & 16 & & 15 & & 6 & & 7 & & 1 & & 6 & \\
\hline \multicolumn{13}{|l|}{ Reason of institutionalization } \\
\hline Abandonment & 30 & \multirow{3}{*}{0.732} & 30 & \multirow{3}{*}{0.5} & 14 & \multirow{3}{*}{$0.0001^{*}$} & 26 & \multirow{3}{*}{0.348} & 3 & \multirow{3}{*}{0.577} & 13 & \multirow{3}{*}{$0.0001^{*}$} \\
\hline Orphanage & 14 & & 13 & & 2 & & 14 & & 1 & & 1 & \\
\hline Disturbed family integrity & 17 & & 9 & & 3 & & 6 & & 0 & & 14 & \\
\hline \multicolumn{13}{|l|}{ Moves between institutions } \\
\hline 1 & 27 & \multirow{3}{*}{0.546} & 39 & & 8 & & 24 & & 4 & & 12 & \\
\hline 2 & 28 & & 13 & 0.0857 & 9 & 0.355 & 15 & 0.331 & 0 & $0.001^{*}$ & 10 & 0.449 \\
\hline 3 & 6 & & 0 & & 2 & & 7 & & 0 & & 6 & \\
\hline Sex of caregiver & & & & & & & & & & & & \\
\hline Male & 13 & 0.202 & 15 & 0.936 & 7 & 0.584 & 4 & 0.941 & 1 & $0.0001^{*}$ & 5 & 0.601 \\
\hline Female & 84 & & 37 & & 12 & 0.584 & 42 & & 3 & & 23 & \\
\hline Stability of caregiver & & & & & & & & & & & & \\
\hline Stable $>6$ months & 42 & 0.972 & 37 & 0.935 & 15 & 0.453 & 32 & 0.914 & 1 & $0.0001^{*}$ & 19 & 0.593 \\
\hline Unstable & 20 & & 15 & & 4 & & 14 & & 3 & & 9 & \\
\hline Length of institutionalization & & & & & & & & & & & & \\
\hline Less than 2 years & 37 & 0.357 & 43 & 0.793 & 15 & 0.366 & 37 & 0.968 & 1 & $0.017^{*}$ & 22 & 0.623 \\
\hline More than 2 years & 24 & & 9 & & 4 & & 9 & & 3 & & 6 & \\
\hline
\end{tabular}

$P<0.05$ Significant, $*$ Significant, $n$ : number, ADHD: attention deficit hyperkinetic disorder.

(b)

\begin{tabular}{|c|c|c|c|c|c|c|c|c|c|c|c|c|}
\hline \multirow{2}{*}{ Variables } & \multicolumn{2}{|c|}{ Conduct disorders } & \multicolumn{2}{|c|}{ Depression } & \multicolumn{2}{|r|}{ Tics } & \multicolumn{2}{|c|}{ Learning disorders } & \multicolumn{2}{|c|}{ Dysthymia } & \multicolumn{2}{|c|}{ Schizophrenia } \\
\hline & $n$ & $P$ & $n$ & $P$ & $n$ & $P$ & $n$ & $P$ & $n$ & $P$ & $n$ & P \\
\hline \multicolumn{13}{|l|}{ Gender } \\
\hline Male & 38 & \multirow{2}{*}{0.907} & 16 & \multirow{2}{*}{0.360} & 1 & \multirow{2}{*}{$0.001^{*}$} & 4 & \multirow{2}{*}{$0.004^{*}$} & 1 & \multirow{2}{*}{$0.001^{*}$} & 0 & \multirow{2}{*}{$0.0001^{*}$} \\
\hline Female & 8 & & 3 & & 1 & & 2 & & 1 & & 1 & \\
\hline \multicolumn{13}{|l|}{ Age (years) } \\
\hline $6-8$ & 11 & \multirow{3}{*}{0.279} & 10 & & 0 & \multirow{3}{*}{0.844} & 3 & \multirow{3}{*}{0.623} & 0 & & 0 & \multirow{3}{*}{0.661} \\
\hline $8-10$ & 12 & & 5 & 0.923 & 1 & & 0 & & 2 & $0.0001^{*}$ & 1 & \\
\hline $10-12$ & 3 & & 4 & & 1 & & 3 & & 0 & & 0 & \\
\hline \multicolumn{13}{|c|}{ Reason for institutionalization } \\
\hline Abandonment & 10 & \multirow{3}{*}{0.620} & 6 & & 1 & \multirow{3}{*}{0.619} & 3 & \multirow{3}{*}{0.086} & 2 & \multirow{3}{*}{0.094} & 1 & \multirow{3}{*}{0.391} \\
\hline Orphanage & 11 & & 8 & 0.290 & 1 & & 2 & & 0 & & 0 & \\
\hline Disturbed family integrity & 5 & & 5 & & 0 & & 1 & & 0 & & 0 & \\
\hline \multicolumn{13}{|l|}{ Moves between institutions } \\
\hline 1 & 16 & \multirow{3}{*}{0.492} & 8 & & 0 & \multirow{3}{*}{0.279} & 1 & \multirow{3}{*}{0.216} & 1 & & 0 & \multirow{3}{*}{0.923} \\
\hline 2 & 6 & & 7 & 0.357 & 2 & & 2 & & 0 & 0.546 & 1 & \\
\hline 3 & 4 & & 4 & & 0 & & 1 & & 0 & & 0 & \\
\hline
\end{tabular}


(b) Continued.

\begin{tabular}{|c|c|c|c|c|c|c|c|c|c|c|c|c|}
\hline \multirow{2}{*}{ Variables } & \multicolumn{2}{|c|}{ Conduct disorders } & \multicolumn{2}{|c|}{ Depression } & \multicolumn{2}{|r|}{ Tics } & \multicolumn{2}{|c|}{ Learning disorders } & \multicolumn{2}{|c|}{ Dysthymia } & \multicolumn{2}{|c|}{ Schizophrenia } \\
\hline & $n$ & $P$ & $n$ & $P$ & $n$ & $P$ & $n$ & $P$ & $n$ & $P$ & $n$ & $P$ \\
\hline \multicolumn{13}{|l|}{ Sex of caregiver } \\
\hline Male & 3 & \multirow{2}{*}{0.538} & 7 & \multirow{2}{*}{0.584} & 0 & \multirow{2}{*}{$0.0001^{*}$} & 1 & \multirow{2}{*}{$0.0001^{*}$} & 2 & \multirow{2}{*}{0.125} & 0 & \multirow{2}{*}{0.215} \\
\hline Female & 23 & & 12 & & 2 & & 5 & & 1 & & 1 & \\
\hline \multicolumn{13}{|l|}{ Stability of caregiver } \\
\hline Stable $>6$ months & 17 & \multirow{2}{*}{0.507} & 10 & \multirow[t]{2}{*}{0.575} & 2 & \multirow{2}{*}{0.123} & 3 & \multirow{2}{*}{$0.018^{*}$} & 0 & \multirow{2}{*}{$0.003^{*}$} & 0 & \multirow{2}{*}{0.235} \\
\hline Unstable & 9 & & 9 & & 0 & & 3 & & 2 & & 1 & \\
\hline \multicolumn{13}{|c|}{ Length of institutionalization } \\
\hline Less than 2 years & 19 & \multirow{2}{*}{0.489} & 13 & \multirow{2}{*}{0.387} & 0 & \multirow{2}{*}{$0.0001^{*}$} & 4 & \multirow{2}{*}{$0.043^{*}$} & 1 & \multirow{2}{*}{$0.001^{*}$} & 0 & \multirow{2}{*}{$0.007^{*}$} \\
\hline More than 2 years & 7 & & 6 & & 2 & & 2 & & 1 & & 1 & \\
\hline
\end{tabular}

$P<0.05$ significant, ${ }^{*}$ Statistically significant.

recurrent physical illness increased the risk of emotional and behavioral problems $[12,27,28]$. Caregiver quality was the most important predictive factor for behavioral problems, which is compatible with previous studies [29]. One of the leading factors that ensure the mental health of children is the quality of the relationship with a caregiver, which is marked by confidence, support, continuity, and warmth. For this reason, caregiver training is identified as one of the most important preventive interventions.

The most prevalent diagnosis was enuresis (23.03\%); a finding very close to that was found by Abolmagd (22.9\%) in orphans compared to (6.7\%) of the school children [30]. On the other hand, El-Ray [31] has found that (41.1\%) of orphans were diagnosed as enuretic. This is explained psycho analytically according to Garfinkel [32] as an expression of passive aggressive behavior, depression, and inability to resolve or contain high levels of anxiety. Meanwhile, Essen and Peckham [33] added that socioeconomic status and stressful life events characteristic of family dysfunction are also more frequently associated with enuresis. Some Egyptian surveys estimated nocturnal enuresis in Egyptian children by $1.9 \%$, out of them, disturbances of home atmosphere was found in (61\%) of enuresis children [34]. It is noticed that children in orphanages demonstrated aggression either passively through enuresis or explicitly as an overt aggressive behavior. Sleep disorders $(10.57 \%)$ were present of all its types and it was noticed that one cause for it may be the hard program put for the children [35]. Current study demonstrated speech disorders affecting $1.5 \%$ of the sample possibly due to anxieties or lack of care in orphanages. Okasha et al. [36], showed that stammers have delayed milestones, aggression, instability and shyness. On the other hand,separation anxiety disorder and depression disorder were found in $7.17 \%$ and $7.17 \%$ of cases, respectively, which may be explained by various variables including all the children had lost one of their parent before the age of 11 years, all were from lower socioeconomic class which are known risk factors for the development of depression [37]. However, These rates are somewhat lower than those found by Fawzy and Fouad (21\% and 58.5\% resp.,) and far lower than those found in other countries, which is attributed possibly, in Egypt, to the sympathy, social support, and religious backgrounds [38]. In Axis II, mental retardation was present in $6 \%$ of our cases, a figure which is nearer to that found by Abolmagd (12.1\%) of orphan children versus (2.7\%) of the control group [30] but far less than that found by El-Ray, who found that (24.4\%) of orphans were mentally retarded [31]. This can be attributed to many possible factors as reported by Grantham-McGregor and Ani [39] including undernutrition, border line intelligent mother, physical or sexual abuse, and/or low previous socioeconomic standards.

\section{Conclusion}

In Egypt, orphanage harbors either true orphans or foundling abandoned by mothers after illegitimate pregnancies. This study showed that children living in orphanages are more prone to suffer from various psychiatric disorders and the stability of caregiver acts as a protective variable. Given the high prevalence of psychiatric morbidities in such institutions and to avoid its hazardous effect on the community, we recommend proper supervision of the orphanages by the supervising authorities, regular training courses for the caregivers to help improving their children caring skills, and psychiatric surveillance for the orphanages must be available and continuous for early detection and treatment of psychiatric disorders. Finally, More studies on orphanages should be carried out including bigger number with longer period of followup in other Egyptian governorates.

\section{References}

[1] N. Erol, Z. Simsek, and K. Münir, "Mental health of adolescents reared in institutional care in Turkey: challenges and hope in the twenty-first century," European Child and Adolescent Psychiatry, vol. 19, no. 2, pp. 113-124, 2010.

[2] S. J. Altshuler and J. Poertner, "The child health and illness profile-adolescent edition: assessing well-being in group homes or institutions," Child Welfare, vol. 81, no. 3, pp. 495$513,2002$.

[3] P. H. Wolff and G. Fesseha, "The orphans of Eritrea: a five-year follow-up study," Journal of Child Psychology and Psychiatry and Allied Disciplines, vol. 40, no. 8, pp. 1231-1237, 1999. 
[4] M. C. Garvin, A. R. Tarullo, M. Van Ryzin, and M. R. Gunnar, "Postadoption parenting and socioemotional development in postinstitutionalized children," Development and Psychopathology, vol. 24, no. 1, pp. 35-48, 2012.

[5] A. L. Trout, K. Casey, M. B. Chmelka, C. DeSalvo, R. Reid, and M. H. Epstein, "Overlooked: children with disabilities in residential care," Child Welfare, vol. 88, no. 2, pp. 111-136, 2009.

[6] P. Vorria, Z. Papaligoura, J. Dunn et al., "Early experiences and attachment relationships of Greek infants raised in residential group care," Journal of Child Psychology and Psychiatry and Allied Disciplines, vol. 44, no. 8, pp. 1208-1220, 2003.

[7] R. Johnson, K. Browne, and C. Hamilton-Giachritsis, "Young children in institutional care at risk of harm," Trauma, Violence, and Abuse, vol. 7, no. 1, pp. 34-60, 2006.

[8] L. C. Leite and P. C. Schmid, "Institutionalization and psychological suffering: notes on the mental health of institutionalized adolescents in Brazil," Transcultural Psychiatry, vol. 41, no. 2, pp. 281-293, 2004.

[9] B. Tizard and J. Hodges, "The effect of early institutional rearing on the development of eight year old children," Journal of Child Psychology and Psychiatry and Allied Disciplines, vol. 19, no. 2, pp. 99-118, 1978.

[10] J. B. McCann, A. James, S. Wilson, and G. Dunn, "Prevalence of psychiatric disorders in young people in the care system," British Medical Journal, vol. 313, no. 7071, pp. 1529-1530, 1996.

[11] A. Ahmad, J. Qahar, A. Siddiq et al., "A 2-year follow-up of orphan's competence, socioemotional problems and posttraumatic stress symptoms in traditional foster care and orphanages in Iraqi Kurdistan," Child, vol. 31, no. 2, pp. 203$215,2005$.

[12] L. Fisher, E. W. Ames, K. Chisholm, and L. Savoie, "Problems reported by parents of romanian orphans adopted to British Columbia," International Journal of Behavioral Development, vol. 20, no. 1, pp. 67-82, 1997.

[13] M. H. El Defrawy, A. M. Abd El Wahab, A. Atef, and M. Abd El Hady, Arabic Translation of Achenbach's Child Behavior Checklist, Faculty of Medicine, University of Suez Canal, Suez City, Egypt, 1995.

[14] L. A. Palen and J. D. Coatsworth, "Activity-based identity experiences and their relations to problem behavior and psychological well-being in adolescence," Journal of Adolescence, vol. 30 , no. 5, pp. 721-737, 2007.

[15] T. X. Tan, R. F. Dedrick, and K. Marfo, "Factor structure and clinical implications of Child Behavior Checklist/1.5-5 ratings in a sample of girls adopted from China," Journal of Pediatric Psychology, vol. 32, no. 7, pp. 807-818, 2007.

[16] J. Biederman, M. C. Monuteaux, E. Kendrick, K. L. Klein, and S. V. Faraone, "The CBCL as a screen for psychiatric comorbidity in paediatric patients with ADHD," Archives of Disease in Childhood, vol. 90, no. 10, pp. 1010-1015, 2005.

[17] Z. S. Lassi, S. Mahmud, E. U. Syed, and N. Z. Janjua, "Behavioral problems among children living in orphanage facilities of Karachi, Pakistan: comparison of children in an SOS Village with those in conventional orphanages," Social Psychiatry and Psychiatric Epidemiology, vol. 46, no. 8, pp. 787-796, 2011.

[18] D. A. Frank, P. E. Klass, F. Earls, and L. Eisenberg, "Infants and young children in orphanages: one view from pediatrics and child psychiatry," Pediatrics, vol. 97, no. 4, pp. 569-578, 1996.

[19] P. Vorriat, S. Wolkind, M. Rutter, A. Pickles, and A. Hobsbaum, "A comparative study of Greek children in longterm residential group care and in two-parent families: I. Social, emotional, and behavioural differences," Journal of
Child Psychology and Psychiatry and Allied Disciplines, vol. 39, no. 2, pp. 225-236, 1998.

[20] P. Roy, M. Rutter, and A. Pickles, "Institutional care: risk from family background or pattern of rearing?" Journal of Child Psychology and Psychiatry and Allied Disciplines, vol. 41, no. 2, pp. 139-149, 2000.

[21] K. Maclean, "The impact of institutionalization on child development," Development and Psychopathology, vol. 15, no. 4, pp. 853-884, 2003.

[22] B. J. Burns, S. D. Phillips, H. R. Wagner et al., "Mental health need and access to mental health services by youths involved with child welfare: a national survey," Journal of the American Academy of Child and Adolescent Psychiatry, vol. 43, no. 8, pp. 960-970, 2004.

[23] M. Tehrani-Doost, Z. Shahrivar, B. Pakbaz, A. Rezaie, and F. Ahmadi, "Normative data and psychometric properties of the child behavior checklist and teacher rating form in an Iranian community sample," Iranian Journal of Pediatrics, vol. 21, no. 3, pp. 331-342, 2011.

[24] D. Cantone, R. Sperandeo, M. N. Maldonato, P. Cozzolino, and F. Perris, "Dissociative phenomena in a sample of outpatients," Rivista di Psichiatria, vol. 47, no. 3, pp. 246-253, 2012.

[25] D. R. Offord, J. F. Aponte, and L. A. Cross, "Presenting symptomatology of adopted children," Archives of General Psychiatry, vol. 20, no. 1, pp. 110-116, 1969.

[26] L. Miller, W. Chan, K. Comfort, and L. Tirella, "Health of children adopted from Guatemala: comparison of orphanage and foster care," Pediatrics, vol. 115, no. 6, pp. e710-e717, 2005.

[27] C. Beckett, B. Maughan, M. Rutter et al., "Do the effects of early severe deprivation on cognition persist into early adolescence? Findings from the English and Romanian adoptees study," Child Development, vol. 77, no. 3, pp. 696-711, 2006.

[28] L. C. Miller, B. Tseng, L. G. Tirella, W. Chan, and E. Feig, "Health of children adopted from Ethiopia," Maternal and Child Health Journal, vol. 12, no. 5, pp. 599-605, 2008.

[29] C. H. Zeanah, "Disturbances of attachment in young children adopted from institutions," Journal of Developmental and Behavioral Pediatrics, vol. 21, no. 3, pp. 230-236, 2000.

[30] S. Abolmagd, "Psychiatric and emotional disorders in a sample of Egyptian orphanage resident children," Egyptian Journal of Psychiatry, vol. 23, pp. 113-123, 2000.

[31] L. A. El-Ray, "Psychiatric and behavioral disorders in a sample of Egyptian orphanage resident children: a preliminary study," Egyptian Journal of Psychiatry, vol. 22, pp. 103-116, 1999.

[32] B. D. Garfinkel, “The elimination disorders," in Psychiatric Disorders in Children and Adolescents, B. D. Garfinkel, G. A. Carlson, and E. B. Weller, Eds., vol. 35, p. 476, Saunders, Philadelphia, Pa, USA, 1990.

[33] J. Essen and C. Peckham, "Nocturnal enuresis in childhood," Developmental Medicine and Child Neurology, vol. 18, no. 5, pp. 577-589, 1976.

[34] A. Okasha, "Focus on psychiatry in Egypt," British Journal of Psychiatry, vol. 185, pp. 266-272, 2004.

[35] J. A. Humphrey, "A study of the etiology of sociopathic behavior," Disease of the Nervous System, vol. 35, no. 9, pp. 432435, 1974.

[36] A. Okasha, Z. Bishry, M. Kamel, and A. H. Hassan, "Psychosocial study of stammering in Egyptian children," British Journal of Psychiatry, vol. 124, pp. 531-533, 1974. 
[37] Ö. Karadă̆ Çaman and H. Özcebe, "Adolescents living in orphanages in Ankara: psychological symptoms, level of physical activity, and associated factors," Turk Psikiyatri Dergisi, vol. 22, no. 2, pp. 93-103, 2011.

[38] N. Fawzy and A. Fouad, "Psychosocial and developmental status of orphanage children: epidemiological study," Current Psychiatry, vol. 17, no. 2, pp. 41-48, 2010.

[39] S. M. Grantham-McGregor and C. C. Ani, "The role of micronutrients in psychomotor and cognitive development," British Medical Bulletin, vol. 55, no. 3, pp. 511-527, 1999. 


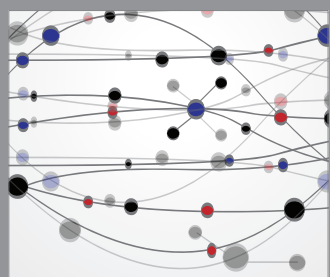

The Scientific World Journal
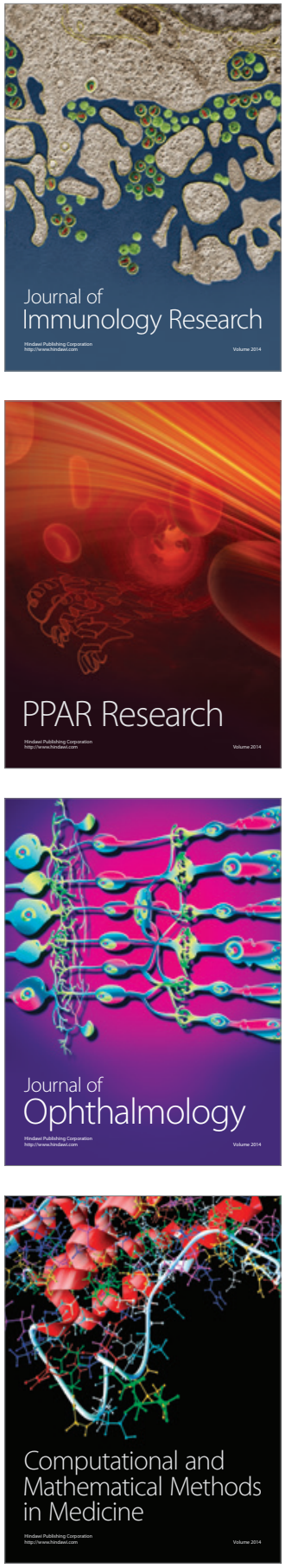

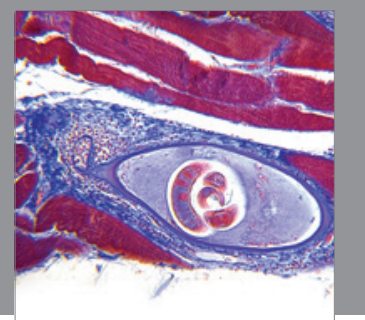

Gastroenterology

Research and Practice
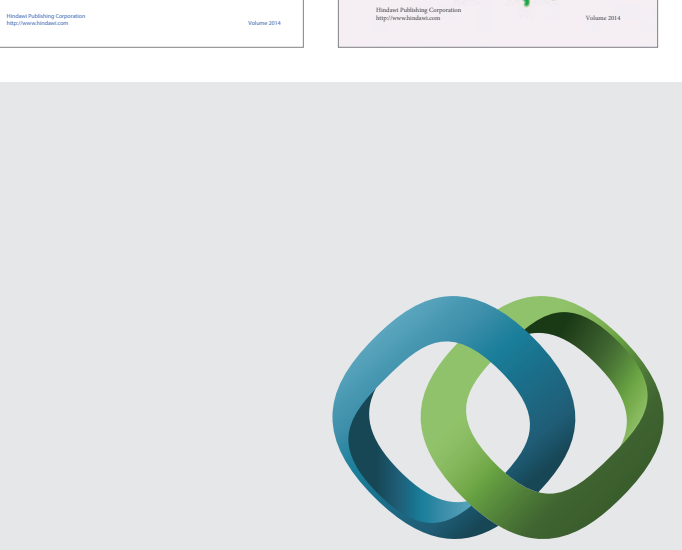

\section{Hindawi}

Submit your manuscripts at

http://www.hindawi.com
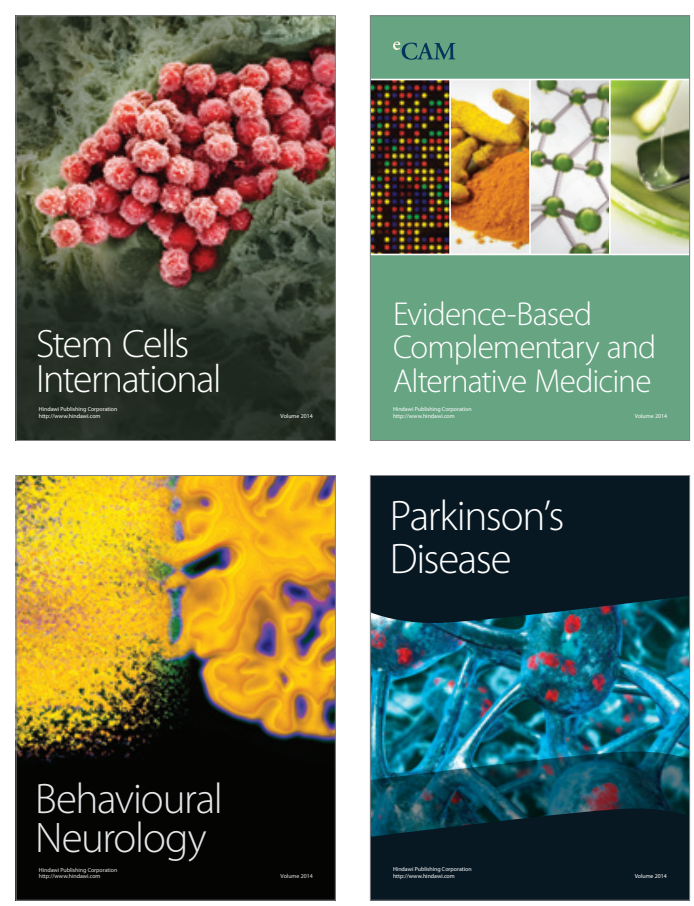

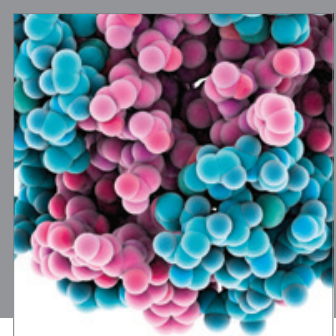

Journal of
Diabetes Research

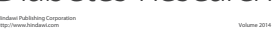

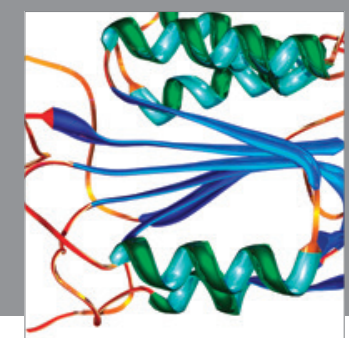

Disease Markers
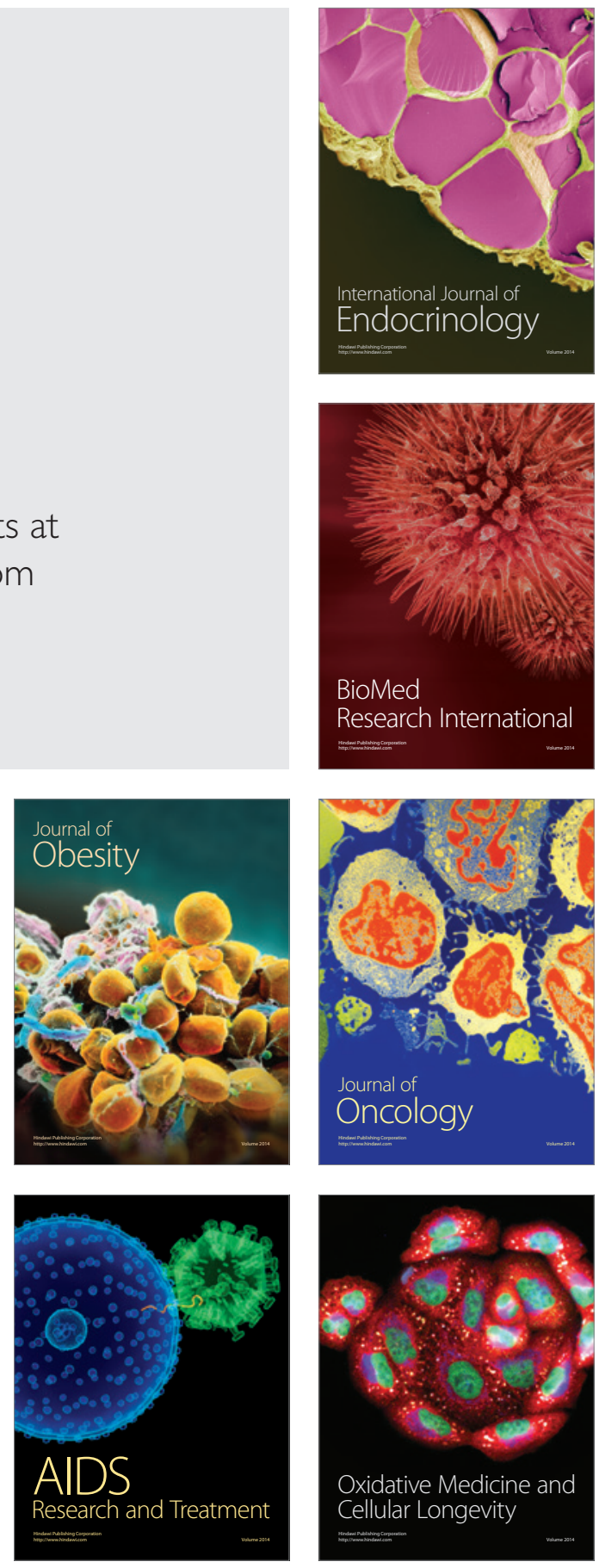